\title{
CONSTRUCCION DE CAPITAL SOCIAL COMUNITARIO Y EMPODERAMIENTO CIUDADANO
}

\author{
ANA INÉS AROSTEGUY PÉREZ*
}

\begin{abstract}
RESUMEN
Este trabajo pretende identificar las características que favorecen la formación de capital social comunitario en la Federación de Organizaciones Juveniles de Consumidores de Concepción (FOJUCC), y demostrar que propicia la construcción de ciudadanía en los jóvenes y el desarrollo sostenible con enfoque de integralidad.

Para realizar esta investigación se utilizaron las teorías del Capital Social Comunitario, para comprobar si existe en la FOJUCC control social, cooperación coordinadora, resolución de conflictos, movilización de recursos comunitarios, legitimación de líderes y trabajo en equipo, además de la Teoría de la Construcción Social de la Realidad para describir los procesos de institucionalización y legitimación de sus acciones.

A través de una metodología cualitativa, basada en corrientes fenomenológicas, se realizaron entrevistas semiestructuradas a ocho miembros de la FOJUCC. Esto permitió comprobar que son capaces de crear normas y sanciones; de desarrollar acciones coordinadas, efectuando una planificación y confiando en el trabajo organizado, entre otros aspectos.
\end{abstract}

\section{Palabras clave: Voluntariado, Desarrollo sostenible CON ENFOQUE DE INTEGRALIDAD, POLÍTICA SOCIAL}

* Periodista chilena, encargada de la Oficina Comunal de Información al Consumidor, Municipalidad de Concepción. E-Mail: tara@esfera.cl. 


\title{
RESUMO
}

\section{A CONSTRUÇÃO DO CAPITAL SOCIAL COMUNITÁRIO E EMPODERAMENTO CIDADÃO}

Este trabalho pretende identificar as características que favorecem a formação do capital social comunitário na Federação das Organizações Juvenis de Consumidores de Concepción, e demonstrar que propiciam a construção da cidadania nos jovens e o desenvolvimento sustentável com enfoque na integralidade. Para realizar esta pesquisa foram utilizadas as teorias de Capital Social Comunitário, para comprovar a existência na FOJUCC de elementos como controle social, cooperação coordenadora, resolução de conflitos, mobilização de recursos comunitários, legitimação de líderes e trabalho em equipe, além da Teoria da Construção Social da Realidade para descrever os procesos de institucionalização e legitimação de suas ações. Através de uma metodologia qualitativa, baseada em correntes fenomenológicas, foram realizadas entrevistas semiestruturadas com oito membros da FOJUCC. Isto permitiu comprovar que seus membros são capazes de criar normas e sanções; de desenvolver ações coordenadas, planejando e confiando no trabalho organizado; entre outros aspectos.

\section{Palavras chave: Voluntariado, DesenVolvimento SuSTENTÁVEL COM ENFOQUE NA INTEGRALIDADE, POLÍTICA SOCIAL}

\section{ABSTRACT \\ BUILDING COMMUNITARY SOCIAL CAPITAL STOCK AND CIVIL EMPOWERMENT}

These notes intend to identify the features that favor the creation of communatry social capityal among the Federation of Juvenile Consumers Organizations of Concepción and prove that it propriates the building of citizenship among young people as well as difensible development focused in integratility. To carry out this research, the theories of Communitary Social Capital were used in order to confirm if among the FJCOC it could be find social control, coordinate co-operation, conflicts resoluction, communitary resources legitimation and team work. As well, the Reality Socila Building Theories were used to describe the institutionality and legitimation of its actions. Throug a qualitative methodology based in phenomenological currents, eight semi structural interviews were carried out ot same number of FJCOC members. This helped to check that they are able to create norms and sanctions and develop planning based in organized work among other aspects.

\author{
KEY WORDS: VOLUNTEERS, DEFENSIBLE DEVELOPMENT FOCUSED \\ IN INTEGRALITY, SOCIAL POLICIES
}




\section{INTRODUCCIÓN}

LA PRESENTE INVESTIGACIÓN QUIERE dar cuenta del trabajo comprometido y silencioso de un grupo de 35 jóvenes penquistas quienes se organizan, desde el año 2001, para desarrollar una serie de actividades que permitan educar a la comunidad sobre materias propias de consumo, específicamente, acerca de las disposiciones de la Ley 19.496 que establece los derechos y deberes de los consumidores en Chile.

Es así como la labor desarrollada por la Federación de Organizaciones Juveniles de Consumidores de Concepción (FOJUCC), hoy goza del reconocimiento de diversas entidades públicas y privadas del país, por cuanto su quehacer permite fomentar las buenas prácticas de consumo y se enmarca dentro de lo que se conoce como el desarrollo sostenible con enfoque de integralidad, cuyos objetivos como señala Cristián Moscoso son «que la vida humana pueda continuar indefinidamente, que los individuos y la sociedad puedan participar y progresar, que las culturas puedan desarrollarse, pero en la que los efectos de la actividad económica se mantienen dentro de límites, de forma que no se destruya la diversidad, la complejidad y el funcionamiento del sistema ecológico que sirve de sostenimiento a la vida, así como el capital social que asegura la gobernabilidad democrática» (Moscoso, 2000:4).

Es este elemento, el capital social, el que explicaría la positiva experiencia de esta Federación. Por lo tanto, la gestión de la FOJUCC, al tener como base la educación y el desarrollo del capital social, se convierte en una de las más exitosas de América Latina en la aplicación del modelo de desarrollo sostenible con enfoque de integralidad. Además, tiene la cualidad de ser una práctica de voluntariado, ya que corresponde a un trabajo libre, planificado, sostenido en el tiempo, y que los jóvenes llevan a cabo en beneficio de su comunidad. Cabe destacar que, de acuerdo a una exhaustiva revisión bibliográfica, los estudios sobre formación de capital social en los jóvenes, no suscitan demasiado interés entre los investigadores. Pese a esta realidad, la CEPAL ha tomado la iniciativa al respecto y en octubre de 2003 presentó su texto «Capital social de los y las jóvenes. Propuestas para programas y proyectos», donde se presentan diversos estudios sobre capital social y juventud, lo que denota el interés de esta entidad por apoyar las investigaciones que se realicen sobre la base de estas experiencias. En Chile este desinterés puede explicarse por aquella percepción popular que señala que los jóvenes tienen una escasa participación ciudadana y que, por opción personal, se mantienen ajenos a la 
contingencia social, política y económica del país.

Sin embargo, el trabajo sistemático de esta investigadora, durante cinco años, con este grupo de jóvenes le ha permitido determinar, en este caso, que esta premisa no es válida y que los jóvenes sí ejecutan acciones que denotan su compromiso con el bienestar de la sociedad. Así lo asegura también Consumers International (CI), una federación internacional que agrupa a más de 160 organizaciones de consumidores de todos los continentes, que destaca que esta experiencia de voluntariado juvenil de Concepción es pionera en el país y también en el mundo, ya que no existen otros ejemplos de estudiantes de educación media y universitaria que dediquen, parte de su tiempo, a realizar campañas de educación sobre materias de consumo.

Este reconocimiento, por parte de Consumers International y la vinculación afectiva hacia los temas de juventud, capital social y desarrollo sostenible, fueron los aspectos que motivaron a esta investigadora a identificar las características que favorecen el proceso de formación del capital social comunitario existente en esta Federación de Organizaciones Juveniles de Consumidores. De esta forma, no sólo se asegura la participación juvenil y la construcción de ciudadanía, sino que además se promueve en los jóvenes la importancia de desarrollar prácticas adecuadas de consumo que garanticen un desarrollo sostenible con enfoque de integralidad.

\section{DELIMITACIÓN DEL PROBLEMA DE ESTUDIO}

Sin duda, uno de los conceptos más utilizados, actualmente, en la formulación de las políticas sociales es el de capital social. Su importancia radica en que es un medio para alcanzar un verdadero Desarrollo Humano, el que es citado por Rosa Helena Stein como «un proceso a través del cual se amplían las oportunidades de los individuos, entre ellas, una vida prolongada y saludable, acceso a la educación y a los recursos indispensables para un nivel de vida digno. Además, concede un gran valor a las libertades política, económica y social, la posibilidad de ser creativo y productivo, el respeto a sí mismo y el disfrute de la garantía de los Derechos Humanos» (Stein, 2003:10). Es así entonces que los aspectos principales que se destacan, en esta definición, son la formación de capacidades y la utilización positiva que deben hacer de ellas las personas.

Estos elementos forman parte inherente de las políticas sociales, ya que al corresponder a una forma de intervención del Estado en la 
sociedad civil se orientan hacia el bienestar de una comunidad. Sus orígenes se remontan a los países europeos donde surgen como una manera de moralizar la economía liberal, dadas las injusticias sociales que provocó la Revolución Industrial. Es así entonces que la noción de política social dentro de un Estado de Bienestar, donde las organizaciones administrativas públicas proporcionan beneficios materiales a aquellas personas que son incapaces de subsistir por sí mismas (desempleados, ancianos, enfermos, etc.); según la socióloga Jeanne Simon, se orientan hacia tres objetivos fundamentales: el evitar conflictos mediante el control de los problemas sociales, fortalecer el rol central del trabajo remunerado y usar la política social como incentivo $\mathrm{y}$, finalmente, promover la lealtad de los ciudadanos hacia el Estado (Simon, 2003).

Esta concepción de las políticas sociales ha experimentado evidentes transformaciones a lo largo de la Historia, hasta llegar a concebirla por el gobierno chileno, en el siglo XXI, a través del Ministerio de Planificación y Cooperación como «el marco ético, político amplio, por medio del cual el Estado se compromete a garantizar la vigencia y el ejercicio del conjunto de los Derechos Humanos, específicamente de los derechos económicos, sociales y culturales, para que las personas mejoren sus vidas, cuenten con mayor libertad e influyan en las decisiones que las afectan» (Mideplan, 2001:79). Es en esta definición de política social donde se encuentra implícito el concepto de capital social, entendido éste por Eduardo Shaw «como un conjunto de normas, reglas, valores éticos y sociales que permiten la interrelación entre individuos y grupos» (Shaw, 2001:1), por cuanto asume la necesidad de operar con estrategias que prioricen el fortalecimiento de la ciudadanía y reconozcan la heterogeneidad de los ámbitos de intervención que abordan las políticas sociales. Por eso, además de privilegiar la inversión social en detrimento de la asistencialidad, la política social actual identifica un conjunto de grupos prioritarios (GGPP): mujeres, niños, indígenas, personas con discapacidad, adultos mayores y, por supuesto, los jóvenes. Esto explica la importancia de elaborar políticas especiales para estos grupos focalizados.

Alan Touraine (1996) señala que el principal objetivo de una política social de juventud es incrementar en los jóvenes la capacidad de comportarse como actores sociales, es decir, como personas que intentan realizar objetivos personales en un entorno constituido por otros actores, el que conforma una colectividad a la que se sienten pertenecientes y cuya cultura y reglas de funcionamiento institucional hacen 
suyas, aunque sólo sea una parte.

A su vez, Óscar Dávila y Claudio Silva (1999) agregan que durante mucho tiempo la política social chilena entendió que quienes se beneficiaban de algunos servicios, prestaciones o asistencia de la red de apoyo social se constituían en beneficiarios, en alguien que por carencia o déficit social adquiere el privilegio de unos derechos. Esta visión es la que no debe primar en las políticas sociales para los jóvenes, ya que se debe propender a considerarlos como sujetos de derecho, o sea, como señalan Óscar Dávila y Claudio Silva se debe «cambiar el eje asistencial por uno que se direccione en la lógica de lo que suele llamarse protagonista o participante para el caso de los jóvenes» (Dávila y Silva, 1999:10).

Entre las recientes y renovadoras propuestas para desarrollar programas sociales, en un contexto de recursos limitados se considera la del capital social. Uno de los autores que alcanza mayor notoriedad en sus trabajos sobre capital social es para Óscar Dávila y Carmen Gloria Honores (2003) Robert Putnam, quien lo concibe como «el grado de confianza existente entre los actores sociales de una sociedad, las normas de comportamiento cívico practicadas y el nivel de asociatividad que caracteriza a esa sociedad. Estos elementos evidencian la riqueza y la fortaleza del tejido social interno de una sociedad» (Dávila y Honores, 2003:179).

De acuerdo a las premisas anteriores, se puede colegir que tanto el capital social como las acciones de voluntariado que realizan los jóvenes chilenos son dos aspectos de las políticas sociales que no han sido lo suficientemente analizados por los investigadores sociales, por lo que se desconoce cómo se crea este recurso tan valioso en las organizaciones juveniles de voluntariado. Como se expondrá en este estudio, en Chile el voluntariado es una práctica que está comenzando recién a ser valorada. De acuerdo a lo señalado por la psicóloga, María Soledad Aravena, éste ha permanecido invisible para la sociedad durante mucho tiempo y sólo comenzó a cobrar notoriedad en el 2001, cuando la Organización de Naciones Unidas celebró el Año Internacional del Voluntariado (Aravena, 2004:01).

Hugo Cabrera (2004) enfatiza que, en los últimos años, se ha registrado una marcada tendencia, especialmente promovida por los gobiernos y las agencias internacionales, a «valorar el voluntariado en términos de su contribución al ejercicio de la ciudadanía y de la participación de las personas. También en tanto expresión de la cooperación y del capital social» (Cabrera, 2004:01). 
Por eso, el objetivo general de este estudio es identificar las características que favorecen la formación del capital social existente en la Federación de Organizaciones Juveniles de Consumidores, mediante la descripción de algunos de sus elementos como el control social, las relaciones de cooperación, la resolución de conflictos, la movilización y gestión de recursos comunitarios, legitimación de los liderazgos y la estructura de trabajo en equipo.

\section{TEORÍAS QUE RESPALDAN LA INVESTIGACIÓN}

Para identificar las características que favorecen el proceso de formación de Capital Social Comunitario en la FOJUCC, las teorías utilizadas en esta investigación son la del Capital Social Comunitario y la Teoría de la Construcción Social de la Realidad.

\section{a) Teoría del capital social comunitario}

John Durston (2000) plantea que el concepto capital social está presente en la estructura de las relaciones entre las personas y en las personas, por lo que surge en el aspecto individual y colectivo. Siguiendo a James Coleman, el autor señala en sus estudios que existen varios tipos de capital social. El capital social individual consta del crédito que ha acumulado una persona en la forma de reciprocidad difusa que puede reclamar en momentos de necesidad, a otras personas para las cuales ha realizado, en forma directa o indirecta, servicios o favores en cualquier momento en el pasado. Este recurso reside no en la persona misma, sino en las relaciones entre personas. El capital social comunitario o colectivo, en cambio, consta de normas y estructuras que conforman las instituciones de cooperación grupal. Reside, no en las relaciones interpersonales diádicas, sino en estos sistemas complejos, en sus estructuras normativas, gestionarias y sancionadoras. (Durston, 2000:19). Agrega que una institución es un sistema de normas y relaciones sociales estables que resultan de las interacciones en un grupo de personas y que tienden a producir la satisfacción de necesidades de algunos o de todos ellos (beneficios para) a un costo menor que en forma individual, o que sería imposible producir de otra manera. Se distinguen de las redes en que poseen mayor complejidad y reúnen las características de un sistema, con una superestructura cultural de normas y un conjunto de relaciones sociales estables. Por eso, las instituciones son sistemas que pueden producir satisfactores para 
las necesidades de un grupo de personas y efectos de retroalimentación. Por eso, este tipo de capital social comunitario beneficia a todas las personas. Además, identifica los beneficios más específicos que se pueden esperar de las instituciones del capital social comunitario: i) La prevención y sanción de los individuos que quieren beneficiarse del capital social sin aportar esfuerzo o recursos propios a su fortalecimiento. ii) La producción de bienes públicos creados por estas formas colectivas de capital social, ya sea prevención de delitos, resolución de conflictos, entre otros (Durston, 200:21-22).

Ambos aspectos deberían estar presentes en la FOJUCC, por cuanto existirían casos donde algunos de sus miembros sólo aspiraban a recibir los beneficios de la federación y no se comprometían con su gestión. Además, también se producirían bienes públicos que responderían al trabajo conjunto de sus miembros.

Dagmar Raczynski y Claudia Serrano señalan que el capital social comunitario tiene un asiento territorial o funcional, es decir «la membresía no depende del reclutamiento de una persona sino de una vecindad estable o una comunidad de intereses definida por un objetivo común. Internamente, hay relaciones fuertes y débiles. Además, el capital social comunitario puede haberse generado por experiencias exitosas de trabajo colaborativo en el pasado» (Raczynski y Serrano, 2005:8). La comunidad se entiende como una vecindad o barrio estable o como un conjunto de intereses de personas con objetivos comunes. En el caso de la FOJUCC, los intereses del grupo apuntan a la educación de la ciudadanía sobre los derechos del consumidor y las materias propias del consumo, objetivo que los caracteriza como una «comunidad». Por eso, se estará en presencia de capital social comunitario cuando un grupo de personas, más allá de sus grupos inmediatos de referencia, ha desarrollado y fortalecido la capacidad de llevar a cabo acciones colectivas por el bien de la comunidad en su conjunto, independientemente del efecto que estas acciones tienen sobre individuos que la conforman.

En este caso, como lo señala Marcos Lorenzelli (2003), el capital social adquiere características de un bien público, pero sin obligación de uso, en la medida de que esta capacidad comunitaria beneficia a todos sus integrantes sin considerar el aporte personal que un individuo ha hecho a la aparición e incremento del capital social comunitario. En la FOJUCC, las decisiones se adoptarían resguardando el beneficio del colectivo, en detrimento de las aspiraciones personales de cada uno de sus miembros. 
Durston (2000) enfatiza que tanto Coleman como Bourdieu señalan que el capital social es un atributo de las colectividades, los grupos sociales y las comunidades. Por lo tanto, se puede concluir que el capital social comunitario no es un recurso individual, sino una forma de institucionalidad social del conjunto y que los participantes de este capital se plantean como objetivo, en forma explícita o implícita, el bien común aunque no necesariamente lo alcanzan. El capital social comunitario se manifestaría en la FOJUCC al ser ésta una comunidad compuesta por 35 miembros que defienden los derechos del consumidor. Considerando los planteamientos anteriores, el mismo autor (2000) enfatiza cuáles son los beneficios que se asocian al capital social comunitario, son los siguientes:

Control social: a través de la adopción de normas compartidas por el grupo y la sanción a los transgresores. Esta situación quedaría de manifiesto cuando se le reprocha a algún miembro de la FOJUCC por su accionar en una situación determinada, la que afecta al total del grupo.

Cooperación coordinada: entre los miembros de un grupo. Se manifestaría en la Federación cuando se planifican las actividades anuales y algunas tareas concretas a ejecutar.

Resolución de conflictos: por líderes o mediante un mecanismo institucionalizado (juntas de vecinos, grupo juvenil, entre otros). En la FOJUCC los conflictos se resolverían a través de propuestas que solucionen los conflictos, las que serían planteadas por los líderes del grupo.

Movilización y gestión de recursos comunitarios: los que se constituyen en bienes públicos.

Legitimación de líderes: dentro del propio grupo de pares.

Generación de ámbitos y estructuras de trabajo en equipo: el trabajo en equipo es uno de los factores que explicaría el éxito del quehacer de la FOJUCC al empoderar a sus miembros con valores y principios que deben traspasar a su realidad local.

De acuerdo a los objetivos de esta investigación, se trabajará con el concepto de capital social comunitario, considerando que se pretende describir el capital social comunitario y su proceso de formación, en una organización o institución juvenil, como es la experiencia de la Federación de Organizaciones Juveniles de Consumidores de Concepción.

b) Teoría de la construcción social de la realidad

Peter Berger y Thomas Luckmann establecen la Teoría de la Cons- 
trucción Social de la Realidad, cuya premisa principal es que la realidad se construye socialmente y que es la sociología del conocimiento la que debe analizar los procesos por los cuales ésta se construye. Por eso, en esta investigación se tomará la realidad tal como se presenta y se aceptarán como datos aquellos fenómenos particulares que se produzcan en su seno.

Ambos autores (2001) señalan que la realidad es «una cualidad propia de los fenómenos que reconocemos como independientes de nuestra propia volición» (Berger y Luckmann, 2001:13). Mientras que, el conocimiento es «la certidumbre de que los fenómenos son reales y que poseen características específicas» (Berger y Luckmann, 2001:13). En este caso se describirá el accionar de la FOJUCC bajo esas premisas, esto es, como un grupo que construye su propia realidad a partir de los fenómenos que experimentan y que definen su accionar.

Berger y Luckmann (2001) señalan que la sociedad puede ser concebida como una realidad objetiva que se caracteriza por dos procesos concretos: la institucionalización y la legitimación. Los orígenes de la institucionalización se encuentran en el proceso de habituación, donde un acto que se repite con frecuencia establece una pauta que es aprehendida por la persona que la ejecuta. Se evidencia también la existencia de una tipificación recíproca, donde se presenta una situación social continua que une las acciones habituales de los individuos, surgiendo un sistema de control social. Luego, éstas se convierten en una realidad objetiva. Aquí cobra una gran importancia el lenguaje como un depositario de una gran suma de sedimentaciones colectivas, que se encarga de objetivizar las experiencias compartidas y de transmitirlas al resto de la comunidad. A continuación, sobreviene un proceso de sedimentación, tradición donde estas experiencias quedan estereotipadas o sedimentadas para luego convertirse en tradiciones. Esto se explica porque el proceso de institucionalización se basa en la repetición de un acto de manera frecuente que crea una pauta que es aprendida por las personas. Pero, esta pauta pasa a un proceso de legitimación cuando se da una tipificación recíproca de acciones por tipos de actores. Por lo tanto, se puede decir que cuando un proceso llega a ser institucionalizado, ejerce sobre el individuo un proceso de coacción.

Ambos autores (2001) agregan que las instituciones se encarnan en la experiencia de los individuos a través de los roles, y al desempeñarlos los sujetos participan en un mundo social y, a la vez, ese mismo mundo cobra realidad para ellos. Por ello, los roles representan el orden institucional, por lo tanto al desempeñarlos estamos legitimando 
la institucionalización. En la FOJUCC, se manifestarían procesos habituales de trabajo que institucionalizan su quehacer, lo que es internalizado por sus miembros y donde el control social desempeña un rol fundamental. El lenguaje común de estos jóvenes es un elemento fundamental que los ayuda a construir su realidad y difundir sus experiencias al resto de la comunidad en general.

El segundo proceso que identifican Berger y Luckmann (2001) es la legitimación, en que se realiza la aceptación de un conocimiento como útil, y surge cuando las objetivaciones del orden institucional deben transmitirse a una nueva generación. Es así como el universo simbólico se construye mediante objetivaciones sociales. Por eso dicen que este universo es legitimador en cuanto:

— Resguarda el orden institucional junto con la biografía individual.

- Ordena la historia y ubica los acontecimientos colectivos dentro de una unidad coherente que incluye el pasado, el presente y el futuro.

- Establece una memoria que comparten todos los individuos socializados.

— Establece un marco de referencia común para la proyección de las acciones individuales.

- Proporciona una amplia integración de todos los procesos institucionales aislados.

Los autores argumentan (2001) que la legitimación es el proceso mediante el cual se transmiten las objetivaciones del orden Institucional a las nuevas generaciones, es decir, es el proceso mediante el cual se explica y justifica el orden institucional, atribuyendo validez a sus significados y roles. Esta legitimación se transmite a través de los universos simbólicos, que son la fuente de la tradición teórica del conocimiento y los significados objetivados socialmente. Estos elementos de la teoría de la construcción social de la realidad, serán los que se consideren al momento de aplicar los instrumentos para realizar esta investigación y describir el capital social comunitario existente en los jóvenes de la FOJUCC.

\section{DISEÑO METODOLÓGICO UTILIZADO}

La división de desarrollo social de la CEPAL, en sus estudios sobre 
capital social de los y las jóvenes de Latinoamérica de octubre de 2003, expone una serie de experiencias vinculadas a ambos conceptos donde se utiliza una metodología cualitativa para profundizar en los aspectos de formación, beneficios e impactos del capital social en los jóvenes. Por ello, esta investigación continuará esta tendencia y utilizará una metodología cualitativa considerando, además, que produce datos descriptivos al considerar los discursos de las personas, escritos o hablados; es inductiva, ya que los investigadores comienzan su trabajo con pautas de datos $\mathrm{y}$, además, los escenarios, grupos o personas son percibidos como un todo en una perspectiva holística.

Es así como este estudio se enmarca dentro de lo que corresponde a las corrientes fenomenológicas, las que según Ana María Rusque «abordan el objeto de estudio, el fenómeno, como una experiencia concreta del hombre, tan libre como se pueda de proposiciones conceptuales» (Rusque, 1999:101). Por eso, el fenomenólogo, como lo explican Steven Taylor y Robert Bogdan (1996) busca «entender los fenómenos sociales desde la propia perspectiva del actor y examina el modo en que se experimenta el mundo».

La realidad que importa es lo que las personas perciben como importante. Además, busca comprensión por medio de métodos cualitativos como la observación participante, la entrevista en profundidad y otros, que generan datos descriptivos (Taylor y Bogdan, 1996:16). En esta investigación se identificará la esencia del fenómeno de formación de capital social comunitario en la FOJUCC, de manera descriptiva y basándose en las experiencias vividas por los jóvenes que la constituyen. De esta manera se podrá apreciar de una mejor forma la interacción entre sus integrantes y entre éstos con la sociedad. Por ello, la investigación se centra en esta visión fenomenológica, considerando la necesidad de comprender cómo un grupo de jóvenes es capaz de realizar un cambio en sus concepciones de ciudadanía y participación y como estas influencias se internalizan en los nuevos integrantes de la FOJUCC.

Este estudio, desde el punto de vista temporal, es un estudio transversal, ya que pretende describir el fenómeno aquí y ahora. Basándose en las diferentes técnicas de recolección de información con que cuenta la investigación cualitativa, se utilizará en este estudio la entrevista semiestructurada para trabajar con los miembros de la Federación de Organizaciones Juveniles de Consumidores.

\begin{tabular}{|c|c|c|}
\hline DIMENSIONES & INDICADORES & PREGUNTAS \\
\hline Control social. & $\begin{array}{c}\text { Normas y sancio- } \\
\text { nes que aplica el }\end{array}$ & ¿Cuáles son las normas que rigen el funcionamiento de \\
la FOJUCC?
\end{tabular}




\begin{tabular}{|c|c|c|}
\hline & grupo. & $\begin{array}{l}\text { ¿Qué sucede cuando estas normas son transgredidas } \\
\text { por uno de sus integrantes? }\end{array}$ \\
\hline $\begin{array}{l}\text { Cooperación } \\
\text { coordinadora. }\end{array}$ & $\begin{array}{l}\text { Planificación de } \\
\text { actividades. }\end{array}$ & $\begin{array}{c}\text { ¿Cómo se planifican las acciones de la FOJUCC? } \\
\text { ¿Quiénes participan en dichas acciones? } \\
\text { ¿Cómo se organiza el trabajo en esas acciones? } \\
\text { ¿Confía Ud. en los miembros de la FOJUCC para la } \\
\text { asignación de las tareas? }\end{array}$ \\
\hline $\begin{array}{l}\text { Resolución de } \\
\text { conflictos. }\end{array}$ & $\begin{array}{c}\begin{array}{c}\text { Acuerdos y solu- } \\
\text { ciones que toma } \\
\text { el grupo. }\end{array} \\
\end{array}$ & $\begin{array}{c}\text { ¿Cuáles son los conflictos que se presentan en la } \\
\text { FOJUCC? } \\
\text { ¿Cómo se resuelven esos conflictos? }\end{array}$ \\
\hline $\begin{array}{l}\text { Movilización } \\
\text { y gestión de } \\
\text { recursos } \\
\text { comunitarios. }\end{array}$ & $\begin{array}{l}\text { Cualidades de las } \\
\text { acciones empren- } \\
\text { didas con la } \\
\text { comunidad. }\end{array}$ & $\begin{array}{c}\text { ¿Cuál es el objetivo de las actividades desarrolladas en } \\
\text { la comuna por la FOJUCC? } \\
\text { ¿Qué tipo de actividades se ejecutan? } \\
\text { ¿A quiénes van dirigidas? } \\
\text { ¿Qué acciones ha desarrollado Ud.? } \\
\text { ¿Cuál es el aporte de la FOJUCC a la comunidad? }\end{array}$ \\
\hline $\begin{array}{l}\text { Legitimación } \\
\text { de líderes. }\end{array}$ & $\begin{array}{c}\begin{array}{c}\text { Existencia de } \\
\text { líderes en el } \\
\text { grupo. }\end{array} \\
\end{array}$ & $\begin{array}{l}\text { ¿Existen líderes al interior de la FOJUCC? } \\
\text { ¿Qué características tienen? } \\
\text { ¿Cómo se llega a ser líder en la FOJUCC? }\end{array}$ \\
\hline $\begin{array}{l}\text { Estructura del } \\
\text { Trabajo en } \\
\text { Equipo } \\
\end{array}$ & $\begin{array}{c}\text { Características del } \\
\text { Trabajo en Equi- } \\
\text { po. }\end{array}$ & $\begin{array}{c}\text { ¿Existe trabajo en equipo en la FOJUCC? } \\
\text { ¿Cómo es este trabajo en equipo? } \\
\text { ¿Con quiénes se relaciona para efectuar este trabajo? }\end{array}$ \\
\hline $\begin{array}{c}\text { Proceso de } \\
\text { institucionali- } \\
\text { zación. }\end{array}$ & $\begin{array}{c}\text { Actividades } \\
\text { desarrolladas por } \\
\text { la FOJUCC. } \\
\text { Lenguaje caracte- } \\
\text { rístico de la } \\
\text { FOJUCC. }\end{array}$ & $\begin{array}{c}\text { ¿Cómo califica las acciones emprendidas por la FOJUCC? } \\
\text { ¿Cree Ud. que dichas acciones han permitido a la FOJUCC } \\
\text { posicionarse dentro de las organizaciones sociales? } \\
\text { ¿Cuáles cree Ud. que son las ventajas del trabajo desarro- } \\
\text { llado por la FOJUCC? } \\
\text { ¿Cuáles son las desventajas del trabajo desarrollado por } \\
\text { la FOJUCC? } \\
\text { ¿Qué significa para Ud. pertenecer a la FOJUCC? } \\
\text { ¿Qué ha aprendido Ud. a partir de su trabajo en la } \\
\text { FOJUCC? }\end{array}$ \\
\hline $\begin{array}{l}\text { Proceso de } \\
\text { legitimación. }\end{array}$ & $\begin{array}{l}\text { Tipo de tareas } \\
\text { ejecutadas por los } \\
\text { jóvenes. } \\
\text { Hechos relevantes } \\
\text { de la FOJUCC. }\end{array}$ & $\begin{array}{c}\text { ¿Cómo evalúa su experiencia en la FOJUCC? } \\
\text { ¿Qué opina su familia del trabajo que desarrolla en la } \\
\text { FOJUCC? } \\
\text { ¿Qué tipo de tareas son las que desarrolla dentro de la } \\
\text { FOJUCC? } \\
\text { ¿Cómo era el trabajo de la FOJUCC en un comienzo? } \\
\text { ¿Cuáles eran los problemas que existían? } \\
\text { ¿Ha percibido ciertos cambios en el trabajo de la } \\
\text { FOJUCC? } \\
\text { ¿Cuál es para Ud. el aspecto más valioso de la FOJUCC? } \\
\text { ¿Cree que la FOJUCC cumple con la misión de difundir } \\
\text { los Derechos de los Consumidores a los jóvenes? }\end{array}$ \\
\hline
\end{tabular}

Además, se efectuará un focus group con tres informantes claves (personas vinculadas a la FOJUCC y que conocen su accionar) y con tres beneficiarios directos (personas que han participado en las actividades ejecutadas por los jóvenes de esta federación). 
Para analizar la información obtenida mediante las entrevistas semiestructuradas que se efectuarán se optó por utilizar una estrategia de análisis temático, donde se extraen y clasifican ciertas partes o fragmentos del discurso. Su objetivo es la captura de toda variabilidad de posicionamientos posibles a propósito de un tema indagado y en una serie de entrevistas. Por ello, la manipulación temática consiste en extraer y clasificar fragmentos del discurso según lo previamente establecido en una malla temática. Luego, los datos son recogidos para clasificarlos en dimensiones a partir de los objetivos específicos planteados. Para cada dimensión se definió un indicador que se responderá a partir de las preguntas efectuadas, de acuerdo a la tabla anterior.

\section{ANÁlisis de LOS RESULTAdOS}

De acuerdo a los datos recogidos y a lo planteado por John Durston, en esta Federación, como colectividad o grupo social, existe Capital Social si se considera que sus miembros desarrollan y valoran su participación activa en tareas de educación, difusión, capacitación y orientación. Ellos consideran también que la confianza, la cooperación y las relaciones de reciprocidad son elementos básicos del accionar de la FOJUCC porque, de lo contrario, no realizarían un trabajo en equipo. Además, reconocen que existen líderes al interior del grupo y que para resolver los conflictos que presenten, al no respetarse las normas internas, existen sanciones que se aplicarán en el momento.

El tipo de Capital Social de la FOJUCC es Comunitario si se considera que ésta es una institución, donde existen relaciones estables entre sus miembros, en la que se sanciona a aquellos que quieran beneficiarse del capital social sin contribuir a su fortalecimiento y la que es capaz de producir bienes públicos, ya sea la educación a la comunidad sobre los temas de consumo, la creación de una conciencia ciudadana y el reconocimiento al trabajo que llevan a cabo estos jóvenes. Cabe destacar que este grupo se conformó para educar y enseñar a los jóvenes y a la comunidad en general, sobre la Ley del Consumidor, lo que apunta a lograr el bien común. Sin embargo, y como lo señala Durston, también los beneficia a ellos. Según este autor, para determinar cuáles son los beneficios del Capital Social Comunitario y que permiten su proceso de formación en la FOJUCC, se consideraron en esta investigación las siguientes dimensiones.

a) Control social 
En esta Federación existen normas que comparten sus integrantes y que deben ser cumplidas para no recibir sanciones. Estas normas no están expresadas de manera formal o por escrito, sin embargo ellos las reconocen como el compromiso e interés por trabajar, la responsabilidad, la dedicación, la participación, la convicción por el trabajo que realizan y el deseo de ayudar a la gente a que conozcan sus Derechos como consumidores y otras materias de consumo. Si alguno de ellos no cumple con estas normas, primero se establece un diálogo informal para conocer las razones de su comportamiento. Luego, si el cambio no se produce, se le asignan menos tareas, se le deja de llamar y así, finalmente, se le excluye del grupo. Esto demuestra la existencia indiscutible del control social que pueden aplicar todos los integrantes de la Federación, en un momento determinado.

\section{b) Cooperación coordinadora}

Los integrantes de la federación planifican las actividades que realizan en sus reuniones de asamblea una vez al mes y todos opinan. Las acciones se dirigen a los jóvenes y estudiantes, principalmente, y a toda la comunidad. El trabajo de la federación se organiza mediante los departamentos o áreas (educación, difusión, sistematización), y cuando existe desacuerdo es el directorio central el que toma la decisión final, considerando la voz de la asamblea. La cooperación coordinadora se manifiesta en la confianza que se da en los jóvenes de la FOJUCC, y que para ellos resulta fundamental para el éxito de su trabajo, cuando deben prestar colaboración para la realización de una actividad planificada por otra organización. Además, cabe recordar que todos participan y asumen roles definidos al momento de concretar una actividad de la federación.

\section{c) Resolución de conflictos}

Los conflictos que se presentan en la federación son fácilmente reconocidos por sus miembros, corresponden a la falta de dinero para efectuar sus acciones, la carencia de un lugar físico para reunirse mensualmente y la diversidad de criterios $\mathrm{u}$ opiniones que se presentan debido a la diversidad de sus integrantes. Por eso, se enfrentan de inmediato, de manera personal y a través de la Asamblea cuando hay una diferencia de opinión. Sin embargo, en el caso de los anteriores, 
sólo han podido paliarlos, pero no darles solución definitiva. Se espera que esto pueda materializarse en el futuro, gracias al aporte de los miembros pasivos.

\section{d) Movilización y gestión de recursos comunitarios}

Sin duda, las acciones de la FOJUCC se dirigen hacia la comunidad, preferentemente hacia el grupo etario juvenil (15-29 años) que pertenece a establecimientos educacionales de enseñanza media. Sin embargo, su trabajo también se extiende hacia los niños de enseñanza básica y, ahora, esperan llegar a los de prebásica.

$\mathrm{Su}$ objetivo principal como federación es generar un proceso de transformación social que permita hacer de los jóvenes verdaderos ciudadanos y sujetos de derechos al educarlos y capacitarlos en diversas materias de consumo. Por eso, la comunidad recibe una serie de beneficios (bienes públicos para Durston) como la invitación a seminarios, la distribución directa de información, en el centro de la ciudad y varias veces al año, además de la orientación respecto a controversias que mantengan con proveedores de bienes o servicios. Es dable destacar que al ejecutar las clases en los establecimientos educacionales, la comunidad recibe la información a partir de sus propios hijos, nietos, amigos y vecinos por lo que se produce la movilización y gestión de recursos. Es así que el aporte que ellos hacen a su comuna radica en ser una vía para crear una conciencia ciudadana respecto a estas materias y que reconozcan el aporte de los jóvenes a su desarrollo y crecimiento social.

\section{e) Legitimación de líderes}

Los líderes de la Federación son reconocidos y legitimados por el grupo. Existe un consenso respecto a quiénes son (los presidentes de cada una de las seis organizaciones juveniles de consumidores que conforman la FOJUCC y aquellos que llevan más tiempo), cuáles son sus características (jóvenes inquietos por aprender y entusiasmar a los demás, con gran motivación, innovadores en la forma de trabajar, sencillos, solidarios, con ideales nobles, con ganas de cambiar al mundo y con espíritu de servicio que se manifiesta en su calidad de voluntarios de la federación) y el proceso que deben seguir para alcanzar el reconocimiento del grupo (gracias a su activa participación, a sus capacidades, a sus conocimientos, a sus ganas y al proceso de crecimien- 
to interno que haya desarrollado al interior de la FOJUCC, a través de sus años de permanencia.

\section{f) Estructura del trabajo en equipo}

El trabajo en equipo es otro de los pilares en que se basa el accionar de la FOJUCC, al igual que la confianza y el servicio a la comunidad. Este rasgo se evidencia desde la planificación de las actividades que se ejecutan hasta su concreción, por cuanto en todo el proceso se solicita la cooperación voluntaria de los miembros de las diversas organizaciones juveniles de consumidores. La unidad que presenta el grupo, sumada a su convicción por alcanzar los objetivos que persiguen, les hacen desa-rrollar este trabajo en equipo de manera espontánea y cotidiana.

De esta manera, y de acuerdo a la teoría anterior, se puede señalar que el proceso de formación de capital social comunitario se manifiesta a partir de la existencia de las características anteriores, las que se evidenciaron a partir de los discursos de los propios entrevistados.

\section{g) Proceso de institucionalización}

Los entrevistados han construido su propia realidad social, desde los fenómenos que han experimentado como voluntarios de una Federación de organizaciones juveniles de consumidores de Concepción y los cuales van a definir su accionar, esto de acuerdo a la teoría de la construcción social de la realidad de Peter Berger y Thomas Luckmann.

La FOJUCC, al contar con una clara organización y planificación de sus actividades, tiene definido un programa de trabajo que se repite durante todos los años, con ciertas modificaciones pequeñas. Los seminarios, las clases, las jornadas de difusión, están claramente establecidas incluyendo los roles que desempeñarán los jóvenes, los que serán asignados de acuerdo a los departamento o áreas en que les corresponde trabajar. Esto es lo que Berger y Luckmann denominan la habituación.

Estas acciones son para los jóvenes una realidad objetiva. A través del lenguaje se objetivizan estas acciones y se transmiten así a la comunidad. Además, se debe señalar que estos jóvenes trabajan con conceptos técnicos que les permite realizar acciones exitosas.

Todos ratifican que las acciones que emprenden, ya sea de educación, capacitación, difusión y orientación, son positivas para la comu- 
nidad, innovadoras y transgresoras, ya que se convierten en un medio para reivindicar a los jóvenes y evitar la discriminación, además de informar sobre los temas de consumo. Esto les ha permitido posicionarse dentro de las demás organizaciones sociales, al ser más conocidos y recibir el apoyo de diversas organizaciones de consumidores y entidades relacionadas a esta problemática. Es decir, su quehacer se va institucionalizando cada vez más.

Las ventajas de su trabajo están vinculadas a la satisfacción por enseñar a las personas a ser consumidores responsables, crear lazos de amistad y compañerismo, adquirir conocimientos y sean reconocidos por la comunidad como jóvenes que trabajan en estos temas. Estos elementos han sido objetivados a través del lenguaje, lo que ha permitido que se objetivicen las experiencias, de acuerdo a la teoría de los autores anteriores. Sin embargo, reconocen que las desventajas de su quehacer son la falta de dinero, espacio y de visibilidad social para ellos. Es por esto que pertenecer a la Federación les ha permitido desarrollarse como personas, al estar entre pares son capaces de potenciar sus habilidades, de ayudarse mutuamente y de crear una identidad propia que los define y que crea un lenguaje común como lo plantea la teoría de la construcción social de la realidad. Estos rasgos han permitido institucionalizar el quehacer de la FOJUCC, aplicando también el control social cuando estos valores no sean cultivados por sus miembros.

\section{h) Proceso de legitimación}

Los jóvenes reconocen que su experiencia en la FOJUCC es buena, provechosa y gratificante, porque han aprendido conocimientos que les son útiles, han podido relacionarse con otras personas y enseñado a la comunidad contenidos que no conocían. Ellos han aceptado sus conocimientos como útiles por lo que ahora desean transmitirlos a las nuevas generaciones para crearles la preocupación por el tema y motivarlos a la acción. Esto es la base del proceso de legitimación que plantean Berger y Luckmann y que se presenta de manera evidente en la Federación. Esto explica el que los jóvenes cuenten la historia de la Federación desde sus orígenes hasta la actualidad, de manera ordenada y narrando aquellos hitos que la marcaron, ya sea su génesis en el año 2001, como su crisis en el 2003 y su proceso de consolidación en los años 2005 y 2006. O sea, ellos comparten una memoria que es transmitida a las nuevas generaciones que se incorporan a la FOJUCC, las acciones individua- 
les se desarrollan dentro de un marco de referencia que es el éxito o el bien de la federación y se integran o incluyen en ella los procesos individuales que experimenta cada organización juvenil de consumidores.

Es así que los jóvenes de la FOJUCC participan en este voluntariado porque han construido una realidad social que les es propia, al reconocer que desarrollan acciones de manera habitual, las que objetivizan esta realidad y así se institucionalizan. Luego, sobreviene el proceso de legitimación de su trabajo en la FOJUCC donde reconocen que han experimentado un proceso en el que han sufrido crisis las que han permitido su consolidación. La legitimación se traduce en el reconocimiento a su historia y a su identidad, en definitiva, al logro del bien común que se proponen alcanzar sus integrantes para toda comunidad. Ambos procesos entonces proporcionan elementos objetivos, de acuerdo a la realidad de cada uno de sus integrantes, los que permiten describir cómo se gesta este capital social comunitario de la FOJUCC.

\section{CONCLUSIONES}

Sólo a partir del siglo XXI el Estado de Chile comenzó a introducir en sus Políticas Sociales, el concepto de capital social como un elemento que favorecía la construcción de ciudadanía y el empoderamiento de la comunidad en los temas que la afectan. Sin embargo, en el caso de la población juvenil, la integración eficaz de estos conceptos a una política social de juventud, elaborada desde el nivel central es actualmente inexistente.

Esta situación ha originado en los jóvenes un sentimiento de abandono social, por parte del Estado y sus instituciones. Por eso, el objetivo general de esta investigación pretendía determinar cuáles son las características que favorecen el proceso de formación de capital social comunitario en la Federación de Organizaciones Juveniles de Consumidores de Concepción, para así fomentar el surgimiento de nuevas experiencias de voluntariado juvenil que contribuyan a formar esta conciencia ciudadana.

Una de estas características, de acuerdo a lo señalado por todos los entrevistados, de una u otra manera, es la existencia de un escenario social donde los jóvenes no son reconocidos y considerados como sujetos de derecho y por eso son excluidos, menospreciados y estigmatizados de manera negativa. Precisamente, es esto lo que ellos tratan de modificar a través del trabajo de voluntariado que ejecutan en la Federación. Están convencidos que al desarrollar acciones que propen- 
dan al bien común, a la aceptación de hábitos de consumo adecuados que lleven al desarrollo sostenible con enfoque de integralidad, podrán crear una nueva generación de ciudadanos que ostentarán una mayor valoración social. Por eso, la creación de la única federación de organizaciones juveniles de consumidores del país es un ejemplo exitoso de cómo la conformación de capital social comunitario puede ayudar a un grupo social a validarse y a adoptar actitudes positivas para el desarrollo de su comunidad y el de los propios miembros que la conforman.

Aunque la FOJUCC aún no ha alcanzado el reconocimiento formal de la comunidad y de los organismos públicos, por no contar con una personalidad jurídica que los respalde, está en camino de alcanzarlo próximamente. Esto constituye otro desafío que los jóvenes tendrán que enfrentar, ya que una vez que la obtengan deberán esforzarse por alcanzar la confianza de la comunidad para que se les asignen proyectos y, con ello, recursos para mejorar su gestión. Sin embargo, los jóvenes están conscientes de que la obtención de estos recursos será limitada para ellos, por el hecho de no adherirse a un conglomerado político o juventud partidista. Situación que, pesar de ser negativa para sus pretensiones, también favorece el proceso de formación de capital social comunitario, al vincularlos por un objetivo que conlleva la producción de bienes públicos como es la educación a los jóvenes sobre materias de consumo. Sin duda, la realidad nacional demuestra que si un grupo juvenil desea alcanzar cierta influencia, debe contar con dicha vinculación, de lo contrario el camino resulta más pedregoso. En el caso de la FOJUCC, los jóvenes tienen claridad respecto a los criterios que rigen el actuar de las organizaciones de consumidores, tanto de Chile como del mundo, y por eso le asignan mucha importancia a la protección de su credibilidad ante la opinión pública. Lo más importante para una organización de estas características es defender a los consumidores que se han visto afectados por empresas privadas o estatales, y para hacerlo no deben tener compromisos con ningún organismo e institución.

También contribuye a la formación de capital social comunitario el construir ciudadanía en los jóvenes a través del fortalecimiento de su autoestima. En las entrevistas, muchos de ellos reconocieron que se sentían excluidos y, muchas veces, minimizados por la sociedad. Esta situación origina un sentimiento de inferioridad, de menosprecio a sus habilidades y de baja autoestima. La FOJUCC contribuye, además, a fortalecer las capacidades de sus miembros, a impulsarlos a tomar nuevos desafíos y decisiones, a resolver los conflictos de manera pacífica, a respetar la diversidad y a cultivar la solidaridad. En definitiva, experien- 
cias como ésta potencian el desarrollo integral de los jóvenes.

Para que surgiera el capital social comunitario fue necesario, para el caso de la FOJUCC, que en un comienzo se contara con el apoyo de una institución, ya sea vinculada al Estado o al gobierno local. Esta entidad fue la Oficina Comunal de Información al Consumidor (OCIC), de la Municipalidad de Concepción, que se comprometió con este desafío y los impulsó a trabajar como voluntarios en estas temáticas. Aunque el proceso de autonomía fue lento, y recién se logró el año 2005 , es necesario que sus actividades fueran apoyadas para que lograran la adopción de formas de trabajo adecuadas y pudieran ejercerlas, de acuerdo a los parámetros de un ordenamiento superior, que los validara ante la sociedad, en este caso, el Plan de Desarrollo Comunal del municipio penquista, años 2000-2004.

Ayudó también a crear este capital social comunitario la participación, pero no cualquiera, una con apellido: activa. Los miembros de la FOJUCC consideran que su participación social se caracteriza por ser activa. Esto se demuestra en que su compromiso por trabajar para el bienestar de la comunidad se lleva a cabo de manera voluntaria y a través de acciones permanentes o sistemáticas, planificadas y con un orden establecido. Ellos hacen una diferencia entre lo que sucede cuando hay elecciones en el país y la gente concurre a las urnas porque hay que hacerlo, y para no tener problemas con la justicia, pero no por un convencimiento interno de que lo que hace contribuye a asegurar una gobernabilidad democrática. Por esto, resulta elemental que los jóvenes estén conscientes de lo que significa una verdadera participación activa para que en el futuro continúen desarrollando acciones donde ésta se manifieste.

Un aspecto importante a considerar es que lejos de la percepción cotidiana de la comunidad, esta investigación demuestra que los jóvenes sí son capaces de adaptar su comportamiento a cierta estructura determinada de normas y sanciones, las que también posibilitan el surgimiento del capital social comunitario. Si bien es cierto que dentro de la federación estas normas no están escritas y formalizadas, ellos sí las reconocen como una serie de características que rigen su comportamiento y, por ende, están conscientes de las sanciones a las cuales se enfrentan cuando no las acatan. Por lo tanto, lejos de lo que se cree, ellos no sólo son capaces de aplicar control social a sus propios pares, sino que de institucionalizarlo al interior de su organización.

Para los miembros de la FOJUCC el tipo de voluntariado que ejecutan en esta organización social, es considerado un trabajo porque 
existe planificación previa, un alto nivel organizacional, no reciben remuneración a cambio y es un servicio que se realiza de manera libre y sistemática. Esto demuestra que el voluntariado se ha ido profesionalizando, cada vez más, por parte de quienes lo practican. En definitiva, el voluntariado crea este tipo de capital social, en la medida en que es un servicio que beneficia a otras personas externas al grupo, creando bienes públicos, aun cuando ellos también se beneficien, como el caso de la FOJUCC.

Por lo tanto, las características que favorecen la formación del capital social comunitario, a todas luces están presentes en este grupo social juvenil y son las que les han permitido posicionarse frente a otras organizaciones sociales vinculadas a los temas de consumo. Sin embargo, resta aún validarse en aquellos organismos locales vinculados a la acción gubernamental. Gracias a la participación, la confianza, la cooperación, la unión, el espíritu de servicio, las motivaciones personales de cada uno de sus miembros y los procesos de institucionalización y legitimación que han tenido lugar al interior de la FOJUCC, es que ésta cuenta con los elementos necesarios para iniciar una nueva etapa de su trabajo de cara a la obtención de su personalidad jurídica, la ampliación de su trabajo a acciones de denuncia pública y la obtención de recursos mediante proyectos presentados en fondos concursables.

Finalmente, si se retoma el argumento inicial, es necesario que el Estado, a través de sus organismos competentes, en este caso el Instituto Nacional de la Juventud, considere estos aspectos al momento de diseñar una política social de juventud que empodere a sus beneficiarios como sujetos de derechos $\mathrm{y}$, que contribuya a la formación de capital social comunitario, de acuerdo a la experiencia de la FOJUCC. De esta manera se estaría dando cumplimiento a lo señalado en el texto del año 2001, «Perspectiva de derechos. Estrategia de fortalecimiento de la política social para la década del 2000», emanado del Ministerio de Planificación y Cooperación.

CONCEPCIÓN (CHILE), MARZO 2007

RECIBIDO: MARZO 2007

ACEPTADO: JUNIO 2007

\section{REFERENCIAS BIBLIOGRÁFICAS}

Berger, Peter y ThOMAs LucKmann (2001): La construcción social de la realidad. Buenos Aires: Amorrortu. 
CABrera, Hugo (2004): «Voluntariado juvenil en Chile, algunos casos interesantes». Santiago: Fundación Marista por la Solidaridad.

DÁVILA LEÓN, ÓSCAR y CARMEN GLORIA HONORES (2003): «Capital social juvenil y evaluación programática hacia jóvenes». Última Década $\mathrm{N}^{\circ} 18$. Viña del Mar: Ediciones CIDPA.

— y Claudio Silva ACEVEDo (1999): «Políticas de juventud y su expresión en lo local». Última Década $\mathrm{N}^{\circ} 11$. Viña del Mar: Ediciones CIDPA.

DURSTON, JOHN (2000): «¿Qué es el capital social comunitario?». Santiago: CEPAL.

LORENZELLI, MARCOS (2003): «VIII Congreso Internacional del CLAD sobre la reforma del Estado y de la administración pública». Panamá.

Ministerio DE PLANIFICACIÓN Y COOPERACIÓN (2001): «Perspectiva de derechos. Estrategia de fortalecimiento de la política social para la década del 2000». Santiago: MIDEPLAN.

MOSCOSO, CRISTIÁN (2000): «Sostenibilidad integral y desarrollo sostenible». Bruselas: Comunicación de la Comisión de las Comunidades Europeas.

RACZYNSKI, DAGMAR y ClAUdia SERRANO (2005): «Seminario: capital social y programas de superación de la pobreza». Santiago: CEPAL.

RUSQUE, ANA MARÍA (1999): «De la diversidad a la unidad en la investigación cualitativa». Caracas: Ediciones Fases y UCV.

SimON Rodgers, JEANNE (2003): «Apuntes asignatura rol del Estado en la sociedad contemporánea». Magíster en Trabajo Social y Políticas Sociales. Concepción.

SHAw, EdUARDO (2004): «Políticas sociales: responsabilidad de todos». Montevideo: Columna DERES.

Stein, Rosa Helena (2003): «Capital social, desarrollo y políticas públicas en la realidad latinoamericana». Brasilia: Departamento de Trabajo Social, Universidad de Brasilia.

TAYLOR, STEVE y ROBERT BOGDAN (1996): «Introducción a los métodos cualitativos de investigación». Buenos Aires: Paidós.

Touraine, Alain (1996): «Juventud y democracia en Chile». Revista Iberoamericana de Juventud $\mathrm{N}^{\circ} 1$. Madrid: OIJ. 